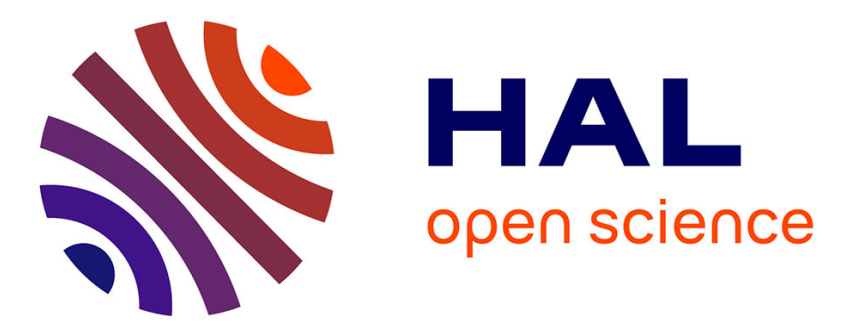

\title{
New Structure for a Six-Port Reflectometer in Monolithic Microwave Integrated-Circuit Technology
}

Frank Wiedmann, Bernard Huyart, Eric Bergeault, Louis Jallet

\section{To cite this version:}

Frank Wiedmann, Bernard Huyart, Eric Bergeault, Louis Jallet. New Structure for a Six-Port Reflectometer in Monolithic Microwave Integrated-Circuit Technology. IEEE Transactions on Instrumentation and Measurement, 1997, 46 (2), pp.527-530. 10.1109/19.571902 . hal-00351725

\section{HAL Id: hal-00351725 \\ https://hal.science/hal-00351725}

Submitted on 10 Jan 2009

HAL is a multi-disciplinary open access archive for the deposit and dissemination of scientific research documents, whether they are published or not. The documents may come from teaching and research institutions in France or abroad, or from public or private research centers.
L'archive ouverte pluridisciplinaire HAL, est destinée au dépôt et à la diffusion de documents scientifiques de niveau recherche, publiés ou non, émanant des établissements d'enseignement et de recherche français ou étrangers, des laboratoires publics ou privés. 


\title{
New Structure for a Six-Port Reflectometer in Monolithic Microwave Integrated-Circuit Technology
}

\author{
Frank Wiedmann, Bernard Huyart, Member, IEEE, Eric Bergeault, Member, IEEE, and Louis Jallet
}

\begin{abstract}
This paper presents a new structure for a six-port reflectometer which due to its simplicity can be implemented very easily in monolithic microwave integrated-circuit (MMIC) technology. It uses nonmatched diode detectors with a high input impedance which are placed around a phase shifter in conjunction with a power divider for the reference detector. The circuit has been fabricated using the F20 GaAs process of the GEC-Marconi foundry and operates between $1.3 \mathrm{GHz}$ and 3.0 GHz.
\end{abstract}

Index Terms-Diode detector, integrated circuit, monolithic microwave integrated-circuit (MMIC), phase shifter, power divider, six-port reflectometer, S-parameter measurement.

\section{INTRODUCTION}

$\mathbf{T}$ HE SIX-PORT reflectometer (SPR) [1] is a passive linear device which measures the complex reflection coefficient $\Gamma$ of a device under test (DUT), using four power readings, followed by a mathematical treatment of the data. As the structure of an SPR is usually much simpler than that of a traditional network analyzer, it is a good candidate for integration.

There have already been some approaches to realize an SPR in MMIC technology. One possibility is to use traditional structures and to replace transmission lines which would be too long for integration by equivalent lumped-element circuits [2]. In general, this approach results in a rather narrow operating bandwidth of the device. Another possibility is to use an essentially resistive structure [3]. The resulting circuit operates over a fairly large bandwidth but shows considerable losses.

The structure presented here is a compromise between these two extremes. It has a medium-range operating bandwidth of typically one to two octaves and a relatively low attenuation of about (6 to 10$) \mathrm{dB}$ between the power source and the measurement port. It also has a low sensitivity to fabrication tolerances of element values, these tolerances being often relatively high in MMIC technology. The circuit is very simple and consists of only few elements, a fact which facilitates greatly its monolithic integration.

\section{The SiX-Port EQUATIONS}

SPR's are linear devices which are usually designed in a way that the power $P_{3}$ detected at the so-called reference port (here called port 3) depends (in an ideal case) only on the

Manuscript received June 20, 1996; revised October 1, 1996. F. Wiedmann is supported by a grant from the Gottlieb Daimler- und Karl Benz-Stiftung.

The authors are with the École Nationale Supérieure des Télécommunications, 75634 Paris Cedex 13, France.

Publisher Item Identifier S 0018-9456(97)01809-3. power wave $b_{2}$ emerging from the measurement port (here called port 2), which is proportional to the power provided by the source connected to port 1 . At the remaining ports 4 to 6 , one measures the powers $P_{4}$ to $P_{6}$ of three different linear combinations of the wave $b_{2}$ which is emerging from the measurement port 2 and the wave $a_{2}$ which is incident on this port. If $A_{i}$ and $B_{i}(i=4,5,6)$ are the coefficients of these linear combinations and $B_{3}$ is the proportionality factor between $b_{2}$ and the wave measured by the reference detector at port 3 , one obtains the following equations for the power ratios $P_{i} / P_{3}$ :

$$
\frac{P_{i}}{P_{3}}=\frac{\left|A_{i} a_{2}+B_{i} b_{2}\right|^{2}}{\left|B_{3} b_{2}\right|^{2}}, \quad i=4,5,6 .
$$

With the definition

$$
q_{i}=-\frac{B_{i}}{A_{i}}
$$

and the reflection coefficient

$$
\Gamma=\frac{a_{2}}{b_{2}}
$$

of the DUT connected to port 2 of the SPR, this equation can also be written in the form (cf., [1])

$$
\left|\Gamma-q_{i}\right|^{2}=\left|\frac{B_{3}}{A_{i}}\right|^{2} \cdot \frac{P_{i}}{P_{3}}, \quad i=4,5,6 .
$$

It can be seen from (4) that $\Gamma$ is given by the intersection of three circles. The centers of these circles are the points $q_{i}$ and their radius is proportional to the ratios $P_{i} / P_{3}$ of the powers measured by the detectors. For an accurate determination of the intersection point $\Gamma$, the points $q_{i}$ must not approach each other too much. This condition generally determines the operating bandwidth of an SPR.

\section{Presentation of the New Structure}

Fig. 1 shows the structure of the new SPR. It consists of a power divider which leads a part of the incident power from the source at port 1 to the matched reference detector $D_{3}$ at port 3 , followed by a phase shifter which is surrounded by three nonmatched diode detectors $D_{4}, D_{5}$, and $D_{6}$, which all present a high input impedance.

In the ideal case where the power divider and the phase shifter are perfectly matched and the input impedance of the power detectors is infinite, the coefficients $A_{i}$ and $B_{i}$ can be 


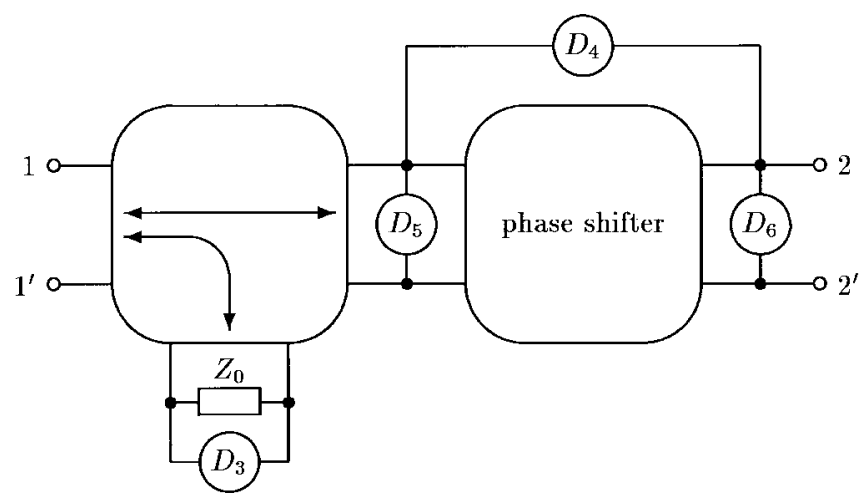

Fig. 1. Structure of the new six-port reflectometer.

written as a function of the phase shift $\varphi$ introduced by the phase shifter

$$
\begin{aligned}
& A_{4}=e^{-j \varphi}-1 \\
& A_{5}=e^{-j \varphi} \\
& A_{6}=1 \\
& B_{4}=e^{j \varphi}-1 \\
& B_{5}=e^{j \varphi} \\
& B_{6}=1 .
\end{aligned}
$$

Using (2), we obtain the following values for the points $q_{i}$

$$
\begin{aligned}
& q_{4}=e^{j \varphi} \\
& q_{5}=-e^{j 2 \varphi} \\
& q_{6}=-1 .
\end{aligned}
$$

The absolute value of the points $q_{i}$ equals one and their phases are $\varphi, 180^{\circ}+2 \varphi$, and $180^{\circ}$, respectively. The optimum value for $\varphi$ is $60^{\circ}$ where the phase difference between each two points equals $120^{\circ}$. Nevertheless, the circuit can be used for a range of $\varphi$ between $20^{\circ}$ and $140^{\circ}$, corresponding to a phase difference between the points $q_{i}$ of at least $40^{\circ}$.

The importance of this SPR design is that the three detectors $D_{4}, D_{5}$, and $D_{6}$ with their high input impedance are working as voltage probes which ideally have no, and in reality have very little, influence on the other parts of the circuit. This structure is very well suited for MMIC technology as the diode detectors generally employed there usually present a high input impedance anyway. Adapting these diode detectors to a lower impedance (e.g., $50 \Omega$ ) as it would be necessary in other SPR designs often requires resistive elements if a larger range of frequencies is to be covered (cf., [2]). The power dissipated in these resistive elements is effectively lost, a problem which is avoided by the structure presented here which uses the high input impedance of the diode detectors advantageously.

\section{ReAlization IN MMIC TEChNOLOGY}

Fig. 2 shows the layout of the new SPR in MMIC technology. The circuit has been fabricated within the EUROCHIP project using the $\mathrm{F} 20 \mathrm{GaAs}$ process of GEC-Marconi and has a surface of $1630 \mu \mathrm{m} \times 1360 \mu \mathrm{m}$.

For the power divider, which can be seen in the layout at the top on the left, the resistive structure shown in Fig. 3 [3]

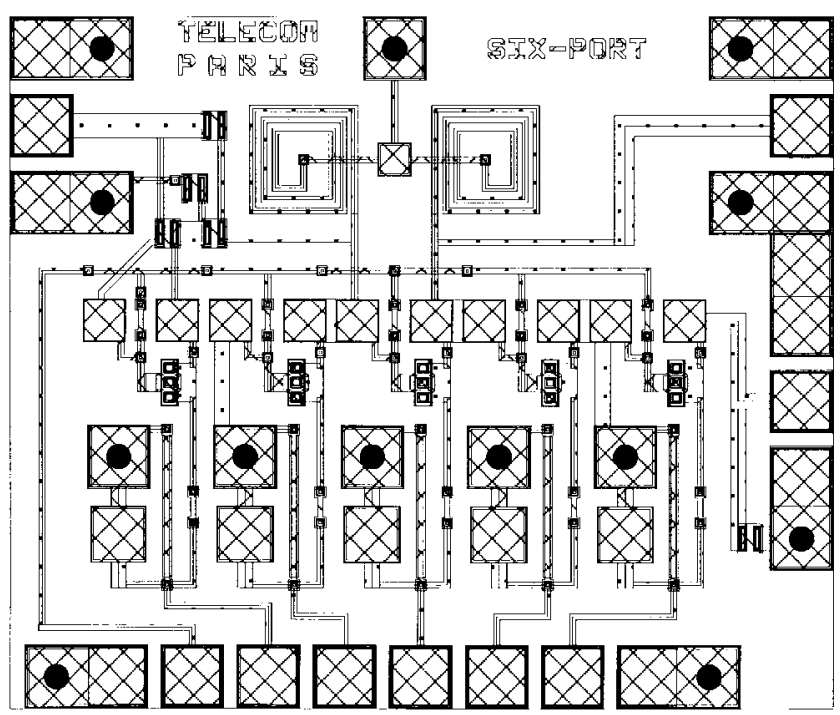

Fig. 2. Layout of the new six-port reflectometer in MMIC technology.
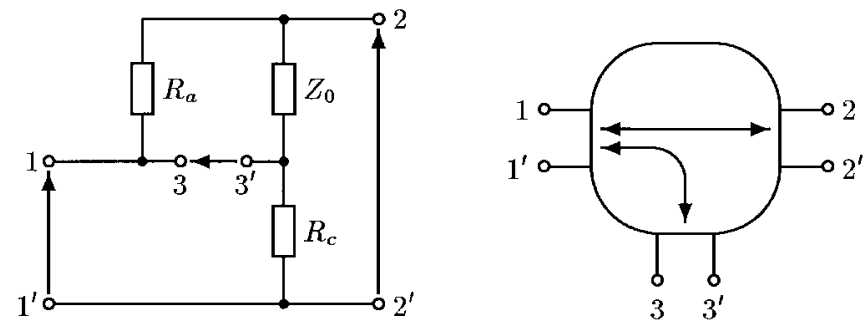

Fig. 3. Structure of the resistive power divider.

(which is similar to a Wheatstone bridge) was chosen because of its ideally unlimited bandwidth. It may be shown that under the condition $R_{\mathrm{a}} R_{\mathrm{c}}=Z_{0}^{2}$, the scattering matrix $S$ of the divider with respect to $Z_{0}$ is given by

$$
S=\left(\begin{array}{ccc}
0 & \frac{1}{1+\frac{R_{\mathrm{a}}}{Z_{0}}} & \frac{1}{1+\frac{R_{\mathrm{c}}}{Z_{0}}} \\
\frac{1}{1+\frac{R_{\mathrm{a}}}{Z_{0}}} & 0 & 0 \\
\frac{1}{1+\frac{R_{\mathrm{c}}}{Z_{0}}} & 0 & 0
\end{array}\right)
$$

i.e., all three ports are matched and ports 2 and 3 are isolated from each other. To obtain an equal power splitting, we chose $R_{\mathrm{a}}=R_{\mathrm{c}}=Z_{0}=50 \Omega$, resulting in an attenuation of $6 \mathrm{~dB}$ in each of the two branches, $3 \mathrm{~dB}$ more than for a lossless power divider but perfectly frequency independent.

The phase shifter, which is situated at the top in the middle, is a simple low-pass circuit consisting of two series inductors and a capacitor to ground. It has been designed to have a characteristic impedance of $50 \Omega$ and a phase shift of $60^{\circ}$ at $1.8 \mathrm{GHz}$.

The diode detectors are placed in the lower part of the circuit. Together, they occupy more than half of the chip's surface. There are five of them, one detector has been added for testing purposes and as a reference for differential mea- 


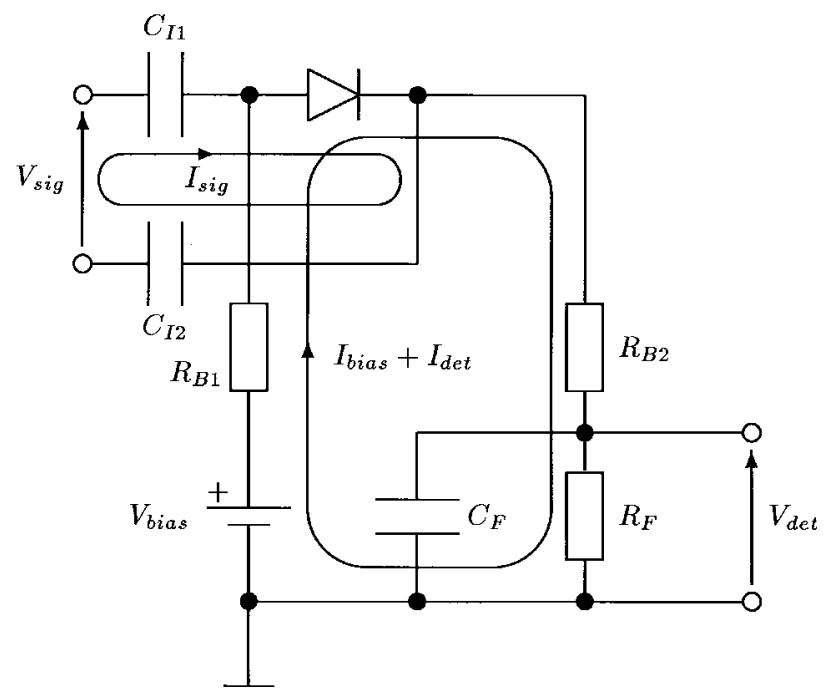

Fig. 4. Structure of the diode detector.

surements, which provides some degree of temperature compensation. None of the inputs of the detectors $D_{3}$ and $D_{4}$ are connected to the circuit ground (see Fig. 1), this is why the structure shown in Fig. 4 [4] was used for the diode detectors. The two capacitors $C_{\mathrm{I} 1}$ and $C_{\mathrm{I} 2}$ at the input serve to isolate the SPR from the direct currents present in the detector. The capacitor $C_{\mathrm{F}}$ and the resistor $R_{\mathrm{F}}$ form a low-pass filter at the output, and the resistors $R_{\mathrm{B} 1}$ and $R_{\mathrm{B} 2}$ serve to isolate the HF signal in the SPR from the detector ground. In order to obtain sufficient sensitivity, the diodes have to be biased by an external voltage source $V_{\text {bias }}$.

The input resistance of the power detectors is high enough so that they have a small influence on the behavior of the circuit and they only cause some additional attenuation. Before fabrication, the circuit had been simulated and optimized, using the complete models for the different components as they were provided by the foundry and thus taking into account effects such as parasitic capacitances, transmission line loss, etc.

It was also confirmed by simulation that fabrication tolerances, which may be of the order of $10 \%$ to $15 \%$ for resistors and capacitors realized in MMIC technology, do not significantly affect the characteristics of the SPR. These variations of the component values may cause a reduced directivity of the power divider or a change in the phase shift and the characteristic impedance of the phase shifter, but these changes are not very large and only influence weakly the important characteristics of the SPR such as the relative position of the points $q_{i}$ or the transmission from port 1 to port 2.

\section{Measurement Results}

The fabricated circuit was examined with an on-wafer measurement system. Attenuation between ports 1 and 2 was $6.9 \mathrm{~dB}$ at $1.3 \mathrm{GHz}$, rising to $9.5 \mathrm{~dB}$ at $3.0 \mathrm{GHz}$ due to the low-pass structure of the phase shifter.

The SPR was calibrated using Engen's six-port to four-port reduction algorithm [5] and a modified version of Stumper's method [6] for finding the initial estimates needed for this

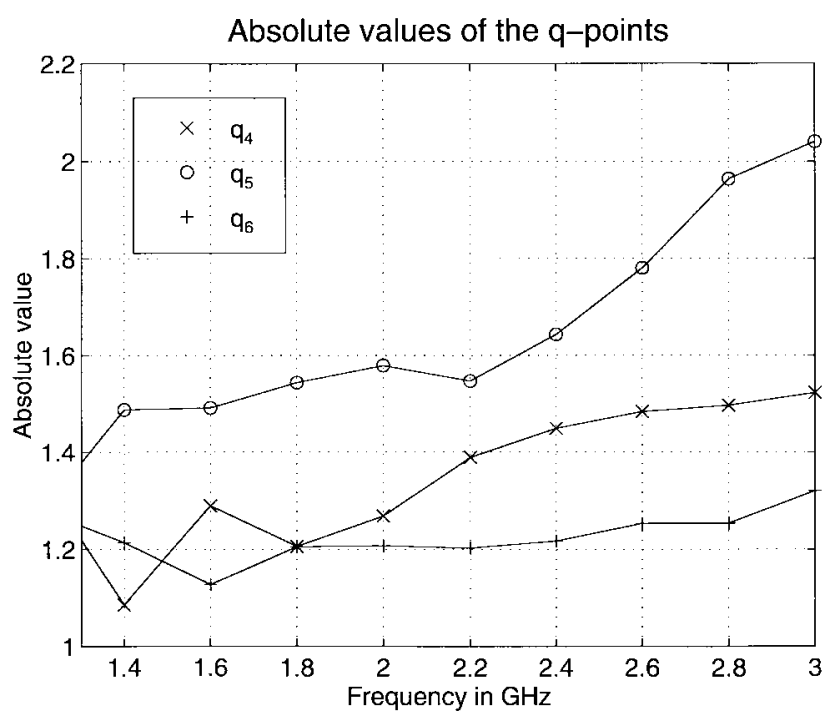

Fig. 5. Measured absolute values of the $q$-points.

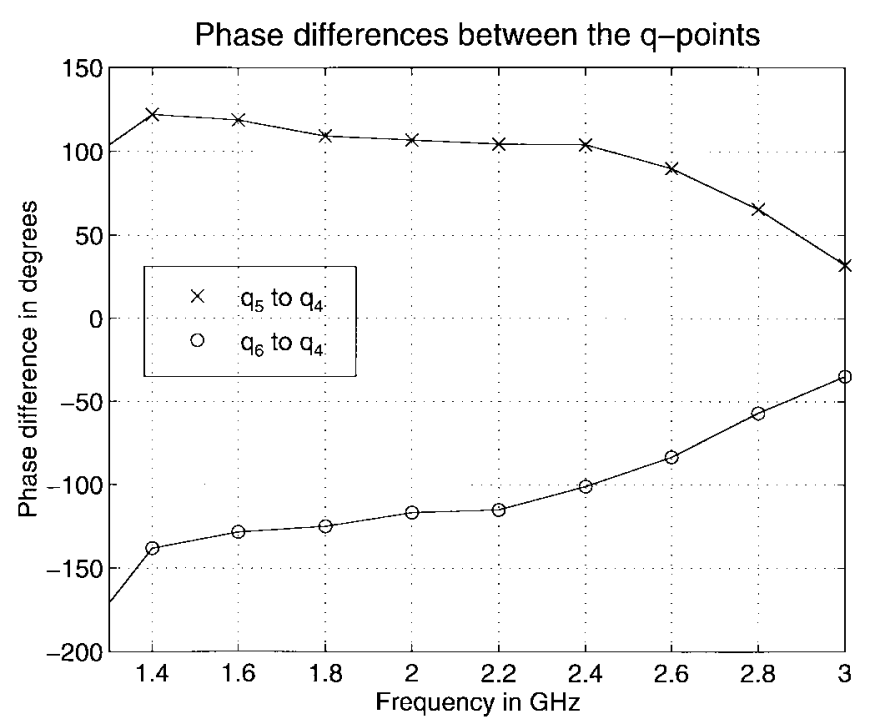

Fig. 6. Measured phase differences between the $q$-points.

algorithm. The calibration of the resulting virtual four-port was then done using three known loads (open, short, and match). The integrated diode detectors were linearized at $2.0 \mathrm{GHz}$ by the method described in [7], which requires neither a reference power meter nor a repeatable attenuation step, using the correction function given in [8].

Fig. 5 shows the measured, absolute values of the points $q_{i}$, they are all situated between 1.0 and 2.1. The absolute values are all larger than the ideal value 1.0 because of additional attenuation between the power detectors and the port 2 of the SPR where the DUT is connected. This attenuation is mainly due to loss in the inductors and the transmission lines and at higher frequencies also to the low-pass structure of the phase shifter. The effect is strongest for the point $q_{5}$ corresponding to the detector $D_{5}$, which has the largest distance from the measurement port 2 .

Fig. 6 shows the measured phase differences between the points $q_{i}$. They are near to the optimum value of $120^{\circ}$ between 


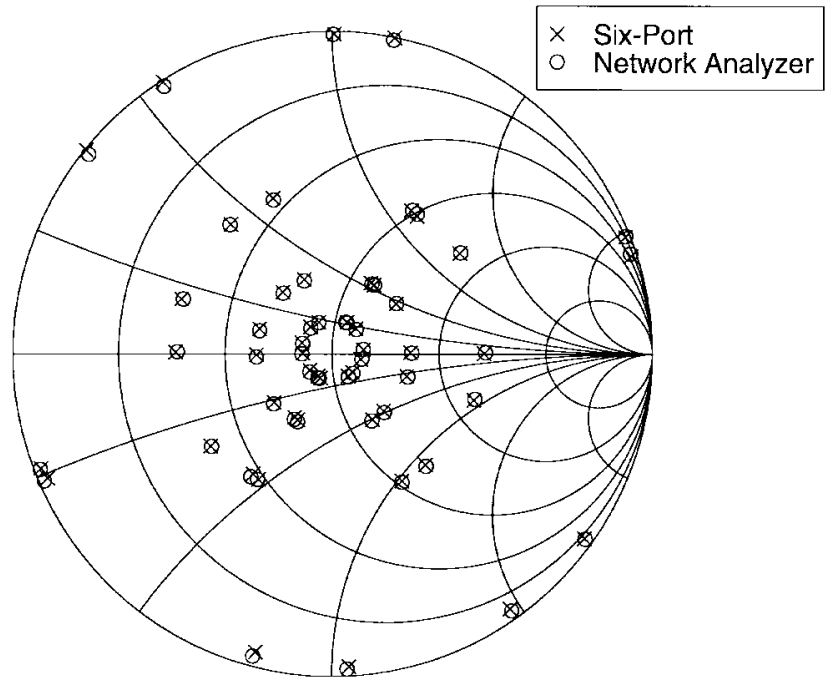

Fig. 7. Comparison of reflection coefficient measurements made at $1.8 \mathrm{GHz}$ with the new six-port reflectometer and a commercial network analyzer.

$1.4 \mathrm{GHz}$ and $2.4 \mathrm{GHz}$, after which they decrease down to a value of about $30^{\circ}$ at $3.0 \mathrm{GHz}$, due to the phase shift $\varphi$ of the phase shifter which increases with frequency.

To evaluate the performance of the new SPR, the reflection coefficients $\Gamma_{\mathrm{SPR}}$ measured with the new SPR were compared to the reflection coefficients $\Gamma_{\mathrm{NA}}$ measured with a commercial network analyzer. The maximum absolute difference $\delta=$ $\left|\Gamma_{\mathrm{SPR}}-\Gamma_{\mathrm{NA}}\right|$ between any two values was 0.02 between $1.6 \mathrm{GHz}$ and $2.6 \mathrm{GHz}$ and 0.04 between $1.3 \mathrm{GHz}$ and $3.0 \mathrm{GHz}$ for loads distributed over the whole Smith chart (transmission lines of different lengths, open and shorted, and in series with $(3,6$, and 10) dB attenuators). Fig. 7 shows as an example the measurements made at $1.8 \mathrm{GHz}$, where the positions of the points can be seen to be virtually identical.

\section{CONCLUSION}

A new simple structure for a six-port reflectometer has been presented which uses nonmatched diode detectors and is well adapted for implementation in MMIC technology. It has an operating bandwidth of typically one to two octaves, a relatively low attenuation between the power source and the measurement port and a low sensitivity to fabrication tolerances of element values.

A MMIC circuit using this structure has been fabricated using the F20 GaAs process of the GEC-Marconi foundry. It operates between $1.3 \mathrm{GHz}$ and $3.0 \mathrm{GHz}$, and comparison with a commercial network analyzer shows a maximum deviation of 0.02 between $1.6 \mathrm{GHz}$ and $2.6 \mathrm{GHz}$ and of 0.04 between $1.3 \mathrm{GHz}$ and $3.0 \mathrm{GHz}$ for test loads distributed over the whole Smith chart.

\section{REFERENCES}

[1] G. F. Engen, "The six-port reflectometer: An alternative network analyzer," IEEE Trans. Microwave Theory Tech., vol. MTT-25, pp. 1075-1080, Dec. 1977.

[2] M. N. Solomon, P. S. Weitzman, C. P. McClay, and H. M. Cronson, "A monolithic six-port module," IEEE Microwave Guided Wave Lett., vol. 2, pp. 334-336, Aug. 1992.
[3] V. Bilík, V. Raffaj, and J. Bezek, "A new extremely wideband lumped six-port reflectometer," in Proc. 20th Europ. Microwave Conf., Budapest, Hungary, 1990, pp. 1473-1478.

[4] B. Huyart, F. Wiedmann, L. Jallet, E. Bergeault, R. Benelbar, and R. G. Bosisio, "Microwave measurement using Wheatstone's bridges," in Proc. 24th Europ. Microwave Conf., Cannes, France, 1994, pp. 928-933.

[5] G. F. Engen, "Calibrating the six-port reflectometer by means of sliding terminations," IEEE Trans. Microwave Theory Tech., vol. 26, pp. 951-957, Dec. 1978.

[6] U. Stumper, "Finding initial estimates needed for the Engen method of calibrating single six-port reflectometers," IEEE Trans. Microwave Theory Tech., vol. 38, pp. 946-949, July 1990.

[7] E. Bergeault, B. Huyart, G. Geneves, and L. Jallet, "Characterization of diode detectors used in six-port reflectometers," IEEE Trans. Instrum. Meas., vol. 40, pp. 1041-1043, Dec. 1991.

[8] C. Potter and A. Bullock, "Nonlinearity correction of microwave diode detectors using a repeatable attenuation step," Microwave J., vol. 36, pp. 272, 274, 277-279, May 1993.

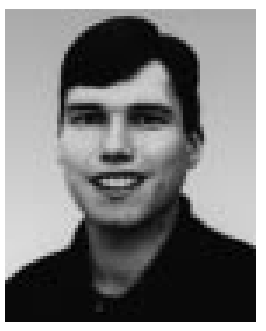

Frank Wiedmann was born in Stuttgart, Germany, in 1968. He received the Diplom-Ingenieur degree in electrical engineering from the University of Stuttgart, Germany, in 1994.

$\mathrm{He}$ then joined the Communications Department of the École Nationale Supérieure des Télécommunications, Paris, France, where he is currently pursuing the Ph.D. degree in electronics and communications. His research interests are in the field of microwave metrology, especially in the development of new structures for six-port reflectometers and of algorithms for their calibration, and in the design of MMIC integrated circuits, on both gallium arsenide and silicon.

Bernard Huyart (M'92) was born in France in 1954. He received the Ingénieurs de Lille, France, in 1977, the Ph.D. degree in physics from the École Nationale Supérieure des Télécommunications (ENST), Paris, France, in 1986, and the research habilitation from the University of Limoges, Limoges, France, in 1995.

He joined the staff of the ENST in 1978, where he is currently a professor. His research activities are the design of active circulators and six-port reflectometers in MMIC or hybrid technology, and applications of six-port systems in metrology, power device, and noise measurements.

Eric Bergeault (M'96) was born in France in 1963. He received the Diplôme d'Études Appofondies (DEA) from the University of Limoges, Limoges, France, in 1987 and the Ph.D. degree in electronics and communications from the National Superior Institute of Telecommunications (ENST), Paris, France, in 1991.

He was a Research Engineer from 1987 to 1990 in the Laboratoire Central des Industries Électriques (LCIE), Fontenay aux roses, France. He joined the ENST in 1991, where he is currently a Teacher and Researcher. His research interest is in the field of microwave instrumentation and he is mainly involved with the six-port network analyzer and characterization of nonlinear devices and applications to the optimization of power amplifiers.

Dr. Bergeault is a member of the Editorial Review Committee of the IEEE TRANSACTIONS ON INSTRUMENTATION AND MEASUREMENT.

Louis Jallet was born in France in 1946. He is a graduate of the National Institute for Telecommunications Administrations, Paris, France.

Since 1975, he has worked in the Department of Electronics and Physics at Télécom Paris (École Nationale Supérieure des Télécommunications), then in the Communications Department as head of the Microwave Group. His research activities primarily concern microwave instrumentation. He has many publications about six-port junction systems and MMIC functions. 